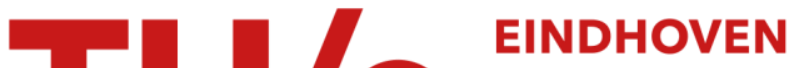

\section{Latent class path model of intention to move house}

Citation for published version (APA):

Jiang, W., Feng, T., \& Timmermans, H. J. P. (2020). Latent class path model of intention to move house. SocioEconomic Planning Sciences, 70, [100743]. https://doi.org/10.1016/j.seps.2019.100743

\section{Document license: \\ TAVERNE}

DOI:

10.1016/j.seps.2019.100743

Document status and date:

Published: 01/06/2020

\section{Document Version:}

Publisher's PDF, also known as Version of Record (includes final page, issue and volume numbers)

\section{Please check the document version of this publication:}

- A submitted manuscript is the version of the article upon submission and before peer-review. There can be important differences between the submitted version and the official published version of record. People interested in the research are advised to contact the author for the final version of the publication, or visit the $\mathrm{DOI}$ to the publisher's website.

- The final author version and the galley proof are versions of the publication after peer review.

- The final published version features the final layout of the paper including the volume, issue and page numbers.

Link to publication

\section{General rights}

Copyright and moral rights for the publications made accessible in the public portal are retained by the authors and/or other copyright owners and it is a condition of accessing publications that users recognise and abide by the legal requirements associated with these rights.

- Users may download and print one copy of any publication from the public portal for the purpose of private study or research.

- You may not further distribute the material or use it for any profit-making activity or commercial gain

- You may freely distribute the URL identifying the publication in the public portal.

If the publication is distributed under the terms of Article 25fa of the Dutch Copyright Act, indicated by the "Taverne" license above, please follow below link for the End User Agreement:

www.tue.nl/taverne

Take down policy

If you believe that this document breaches copyright please contact us at:

openaccess@tue.nl

providing details and we will investigate your claim. 


\title{
Latent class path model of intention to move house
}

\author{
Wen Jiang $^{\text {c, a, }}$, Tao Feng ${ }^{\text {b,c }}$, Harry J.P. Timmermans ${ }^{\mathrm{b}}$ \\ ${ }^{a}$ Chongqing University, NO. 174 Shazheng Street, Chongqing, 400044, China \\ ${ }^{\mathrm{b}}$ Eindhoven University of Technology, PO Box 513, Den Dolech 2, 5600, MB, Eindhoven, the Netherlands \\ ${ }^{\mathrm{c}}$ Key laboratory of new technology for construction of cities in mountain area, Chongqing University, China
}

\section{A R T I C L E I N F O}

\section{Keywords:}

Unobserved heterogeneity

Latent class path model

Intention to move house

Residential satisfaction

\begin{abstract}
A B S T R A C T
This paper proposes a latent class path model to analyse the intention to move house as a function of residential satisfaction, which in turn is influenced by the gap between residential aspirations and reality. Different from the existing literature, which assumes the same structural dependencies apply to all residents with different sociodemographic profiles, we allow for different unobserved classes with different structural dependencies. Class membership is a function of the socio-demographics of individuals. Using data from eight renovated historical blocks in two Chinese cities, the differences influencing the intention to move house between two latent classes are captured. In one class the intention to move is significantly influenced by housing and environmental satisfaction, but this dependency is not found in the other class. The impact of the residential gap on satisfaction also differs between the two classes. Class membership is found to be mainly attributed to having property rights or not and whether respondents are supporting the elderly. Policy and planning implications are provided considering the different residential interests and backgrounds of residents.
\end{abstract}

\section{Introduction}

The study of residential satisfaction and mobility has a long history in urban research. Residential mobility has commonly been explained in terms of residential satisfaction (e.g., [1,2]). The lower the residential satisfaction, the higher the intention to move or the higher the probability to move house. In addition, moving intention or probability of moving house has been modelled as a function of social demographic characteristics of individuals and households, either directly (e.g., [3-5]), or indirectly through residential satisfaction (e.g., [6,7]). In turn, residential satisfaction has been primarily modelled as a function of residential (housing and neighbourhood) attributes (e.g., [8,9]).

Few studies analysed how residential satisfaction is influenced by residential gap, defined as the mismatch between aspiration and perceived reality (e.g., [11]). Often, the relationships mentioned have been examined separately and independently. Only a few studies have applied an integrated approach, combining the relationships in structural equation or path models (e.g., $[7,12]$ ).

In these studies of residential satisfaction and mobility, the issue of unobserved heterogeneity has received only scant attention (e.g., [13, 14]). Variability in part-worth utilities and moving probabilities has predominantly been viewed as a function of observed socio-demographic characteristics. Only a few studies have applied mixed logit models or latent class models to capture unobserved heterogeneity in residential choice behaviour.

These models, however, consider unobserved heterogeneity only in single direct relationships regarding residential satisfaction or mobility. To the best of our knowledge, models that identify latent classes in the complex direct and indirect relationships between different sets of variables have not been developed in the residential mobility literature. It means that studies incorporating unobserved heterogeneity underlying integrated causal structures in which the estimated relationships between the variables vary by class should be a relevant and novel contribution to the state of the art in residential mobility research.

Based on this rationale, this paper formulates a latent class path model (LCP) in which each class represents a different causal structure between the intention to move house, residential satisfaction and residential gap. In line with the definition in the classic residential satisfaction literature [11], residential gap is defined as the gap between aspiration (desired situation) and reality (currently perceived situation). Similar concepts include stress (e.g., [15]), mismatch (e.g., [16]), and deficit (e.g., [17]). Gap-satisfaction theory generally assumes that residential satisfaction is a function of residential gap. Specifically, every individual has certain aspirations regarding his/her house and

\footnotetext{
* Corresponding author.

E-mail address: jiangwen0913@gmail.com (W. Jiang).
} 
experiences the real situation, which may not fully satisfy the aspirations. It is assumed that the mismatch between aspiration and perceived reality influences residential satisfaction [11,18,19].

The LCP model proposed identifies heterogeneity among residents, which is important for planners and policy makers. It should be noted that a proper policy decision in urban planning, especially when it is targeted at a specific group of people, needs further understanding of the responses of individuals with different socio-demographic backgrounds. Identification of the heterogeneity or difference among individuals plays a very important role in the success of policy implementations on different groups of people. This cannot be captured in traditional path analysis which only estimates the average residential interests of all individuals with different socio-demographic profiles.

The model is estimated using data collected from eight historical blocks in two selected Chinese cities. The term historical block and district officially denote the areas in Chinese cities, where historical or cultural buildings gather or present the characteristics and style of a certain historical period. ${ }^{1}$ As historical blocks experienced various levels of renovation, at different renovation stages, residents' aspiration, satisfaction and moving intention vary due to the changing living environment [20] and exhibit more variability compared with other urban areas. In intending to move house, residents in historical blocks encounter more benefits and constraints than those living in other urban areas $[21,22]$. Therefore, historical blocks provide an interesting background for residential mobility studies and model testing.

The remainder of the paper is structured as follows: the next section will review prior research on residential satisfaction and mobility from a methodological perspective. Then, the conceptual model underlying this study will be proposed and the LCP model will be formulated. The fourth section describes the data collection, followed by an interpretation of the results of the model estimation. The last section will draw some conclusions with a discussion of model findings.

\section{Literature review}

Since the 1970s, a large number of residential studies have appeared in the housing and urban planning literature. Central concepts in these studies are residential satisfaction and residential mobility. In this review, we differentiate between studies that conducted a single relationship analysis and those that analysed both direct and indirect relationships between multiple concepts related to residential satisfaction and mobility. After reviewing each of these studies, the issue of unobserved heterogeneity will be discussed.

A further division of these studies can be based on the measurement scale of the dependent variable. Generally, residential satisfaction has been measured on an interval scale. However, some studies have used ordered categorical scales or treated their rating scales as such. Similarly, residential mobility has been measured on an interval scale when authors requested respondents to express the intensity of moving intention or the probability of actual move, while a binary scale is assumed when authors asked respondents to indicate whether or not they have the intention to move house. The specific models used then depend on the measurement scale of the dependent variable.

\subsection{Single relationship analysis}

First, a plethora of studies has applied linear regression analysis to explain residential satisfaction as a function of residential attributes (e. g., [23-28]), or residential gap (e.g., [19]). These studies have implicitly or explicitly assumed that residential satisfaction is measured at an interval scale. The residential attributes were often grouped into housing attributes, neighbourhood attributes and accessibility attributes [10, 48]. In few studies (e.g., [29]), linear regression has also been applied to

\footnotetext{
${ }^{1}$ Ministry of Construction of the People's Republic of China, May 1985.
}

examine the impact of residential gap on satisfaction. A larger residential gap is found to reduce satisfaction.

Second, another stream of research can be isolated that has been concerned with residential mobility, including moving intention and moving behaviour. Some studies have measured the intention to move house (e.g., [2,30]). Usually, the intention to move is assumed to have interval properties, and consequently linear regression models have been the dominant method of analysis. For instance, Earhart and Weber [3] used the multiple regression model to analyse the contribution of home attachment to moving intention. By contrast, when the intention to move house is measured as a binary choice, logistic regression has been used. For instance, Lee et al. [31] applied logistic regression to examine the influence of social-demographics, like gender, tenure and education, on the intention to move. Others, however, assumed these scales only have ordinal or categorical discrete properties and therefore ordered probit and logit models have been used to estimate the relationship between the explanatory variables and the intention to move house. For example, Böheim and Taylor [30] used a random-effect probit model to analyse the determinants of the decision to move house. Kim et al. [2] used a multinomial logit model to analyse the influence of social-demographics, social ties and environmental perceptions on moving propensity.

Rather than measuring intention to move, other studies have examined actual moves. Because in this case the dependent variable is often dichotomous or polytomous, discrete choice models have been predominantly used. Kan [32] applied both the binary and multinominal probit model to test the impact of social capital on households' mobility behaviour from its spatial dimension. Diaz-Serrano and Stoyanova [7] used three probit models to analyse the influence of residential attributes and residential satisfaction on observed moves in 12 countries.

\subsection{Heterogeneity in single relationship analysis}

Most of these studies have implicitly or explicitly assumed that the estimated parameters apply to every individual, implying that unobserved heterogeneity was not taken into account. Although some studies tried to identify the difference between groups of residents, they analysed observed heterogeneity by dividing residents into groups before applying the analytical models. These studies only analyse observed heterogeneity and therefore cannot capture unobserved differences in the estimated relationships. For instance, propensity score matching analysis allows examining the heterogeneity between groups of individuals by controlling for covariates. However, this method classifies residents according to certain attributes before analysing the influence of these attributes on the dependent variable (e.g., [33]).

Only recently, with the development of models accounting for unobserved heterogeneity, this issue has been studied in studies on residential behaviour and preference. Mixed logit models that estimate heterogeneity in taste variation by identifying random parameters have been applied in analysing residential mobility. For example, Rabe and Taylor [13] used two mixed logit models to estimate heterogeneity in moving behaviour with and without the influence of neighbourhood quality adjustment. Dane et al. [14] studied how housing and work attributes influence the intention to move (or not) using a binary mixed logit model. It was found that a high degree of unobserved heterogeneity exists among people with lower education degrees in their intention to move house.

Besides mixed logit models, heterogeneity has been examined using latent class models. Different latent classes, each with a specific utility function, are identified. Class membership is typically predicted as a function of individual characteristics. Latent class analysis was conducted by Burholt [34] to identify the latent groups among the elderly regarding their moving distance using longitudinal data. Later, Ettema [35] used a latent class discrete choice model to estimate the residential preferences of telecommuters. Recently, the interest in examining unobserved heterogeneity has been increasing in housing location choice 


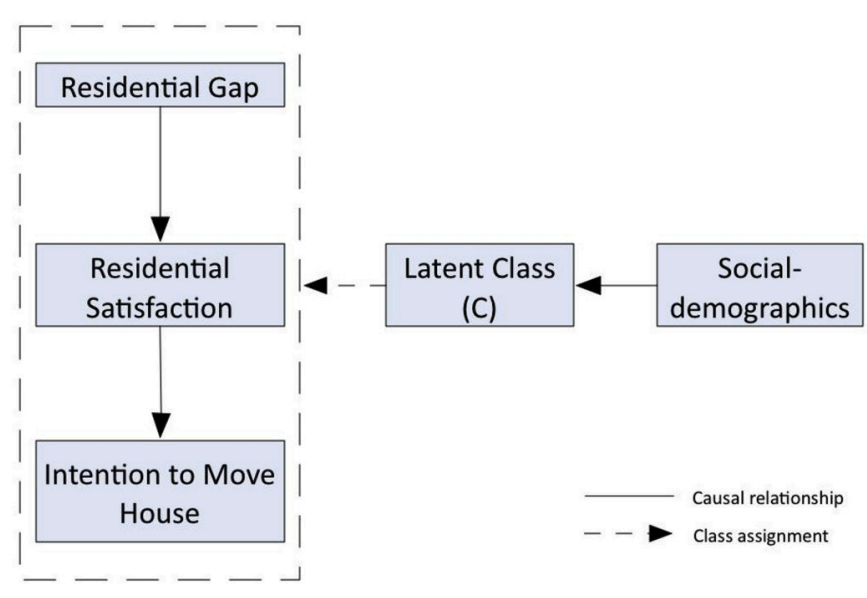

Fig. 1. Conceptual model.

studies [36-39]. The potential advantage of latent class models is that they allow different equations for the identified classes. Therefore, this approach is preferred in the present study.

\subsection{Multiple relationships analysis}

These single dependency models were complemented in residential studies that estimate all direct and indirect relationships between residential attributes, socio-demographics, residential satisfaction and intention to move/actual move. For instance, Speare [40] used a path model to study how social-demographics directly influence residential satisfaction and intention to move and further indirectly influences moving behaviour. This model was later expanded by Speare et al. [15] by adding more individual variables, especially education. Pickvance [41] introduced the concept of lifecycle and investigate how life events and individual factors influence moving intention using a path model. Bach and Smith [42] and Varady [6] expanded and/or tested Speare's path model for different groups of residents, for instance, the elderly. Oh [12] replicated Speare's model by adding social bonding as a latent variable to study the moving intention of the elderly. Jiang et al. [19] used path analysis to study the relationships between residential gap, residential satisfaction, moving intention and social-demographic attributes. Ren et al. [33] used the multi-group SEM approach to test the coefficients of three groups of respondents in an attempt to identify the determinants of residential satisfaction in China. Abe and Kato [43] also used SEM to analyse the influence of individual characteristics and residential environment attributes on residential satisfaction.

\subsection{Heterogeneity in multiple relationships analysis}

Although the studies focusing on multiple relationships can analyse more complicated relationships between the groups of variables, applications of these models in the residential mobility literature have, to the best of our knowledge, not yet considered unobserved heterogeneity between individuals. However, the reasons behind moving intention and behaviour may vary between residents. The direct and indirect relationships between attributes, satisfaction and intention to move may vary among residents (of different socio-demographic profiles). Thus, it may be worthwhile to identify latent classes in the residential decisionmaking process and simultaneously capture differences in the direct and indirect causal relationships. This study sets out to explore that option.

\section{Conceptual framework and model formulation}

\subsection{Conceptual framework}

Following classic gap-satisfaction theory, we assume that a larger residential gap may lead to lower residential satisfaction. As residential satisfaction decreases, the intention to move house increases [12]. Along with the deterioration of the house and the social fabric of neighbourhood, the real situation may become worse. When encountering an attractive house with good accessibilities and facilities, or when life cycle events such as birth of a child change aspirations and needs, the gap between aspirations and perceived reality may increase, leading to lower residential satisfaction. If residents face constraints or restrictions, it may be impossible for them to improve their immediate residential situation or move house. Under such circumstances, they have to adjust their aspirations. However, if there are no constraints, the intention to move house increases with a lower residential satisfaction. Therefore, rather than directly and independently assessing the relationships between residential attributes, residential satisfaction and intention to move house, it is assumed in this study that the intention to move is influenced by residential satisfaction, which in turn is a function of the gap between aspirations and perceived reality (Fig. 1). This paper focuses on intention to move rather than moving behaviour.

In reality, residents with different socio-demographic profiles may have different residential preferences which are influenced by their own backgrounds. Moreover, residents may face different constraints when trying to act on their preferences and achieve their aspirations. In this paper, the heterogeneity between residents is captured by specifying the latent classes in terms of residents' aspiration, residential satisfaction and moving intention. The class membership is treated as a function of social-demographic information which refers to commonly used attributes in the literature on residential satisfaction or mobility. Specifically, personal and household characteristics, such as gender [2], supporting elderly or not [44], tenure $[5,45]$ and education $[46,47]$ are chosen. Moreover, because the renovation condition of historical blocks may affect residents' satisfaction, renovation stage is also included to identify class membership.

It should be noted that this paper mainly focuses on the physical dimension of housing. In spite that voluntary moves are affected by housing, neighbourhood and accessibility [48], housing attributes, compared to other two groups of attributes, are found to have larger influences on residential satisfaction and mobility $[9,28,49]$. The attributes related to house itself and housing surroundings have been found influential in residential mobility $[14,50,51]$. Therefore, to get a good understanding about the influence of physical factors, this analysis mainly considers housing and living environmental attributes.

\subsection{Residential gap index}

The concept of gap plays a key role in the conceptual framework. Following Jiang et al. [19], residential gap is defined in terms of the following gap index:

$g_{i m}=\max \left(0,1-\frac{\left|R_{i m}-A_{i m}\right|}{A_{\text {im }}}\right)$

where an ideal point is assumed for the gap measurement as the gap may not monotonically increase or decrease. For each individual $i$ and attribute $m$, the index first takes the absolute difference between the perceived reality $R_{i m}$ (individual $i$ 's perception of the status of attribute $m$ ) and his/her aspiration $A_{i m}$ (aspired situation). Different from previous residential studies (e.g., [16,52]), this difference is expressed as the ratio to the aspiration. This advantage of this formulation is that the same absolute difference has less influence if the aspiration is high. Next, the index is normalized. For continuous attributes, when the perceived reality $\left(R_{i m}\right)$ approaches the aspiration $\left(A_{i m}\right),\left|R_{i m}-A_{i m}\right| / A_{i m}$ reaches zero and the gap index $\left(g_{i m}\right)$ approaches one, which means the gap between reality and aspiration is the smallest. If reality is much lower than aspiration, the gap index approximates zero and the gap becomes the largest, which leads to the lowest satisfaction as the conceptual model assumes. For categorical variables, a larger gap index refers to a match 
while a smaller index refers to a mismatch. When reality exceeds two times higher than aspiration level, the gap is truncated at zero. Readers may find this normalization counterintuitive. As discussed in Jiang et al. [19], the reason of using a smaller gap index to represent a higher gap is to keep the direction of the sign of the continuous variables consistent with the sign of the categorical variables. Note that as long as the interpretation is correct, this is a non-issue. This gap index is incorporated in the latent class path model that we propose in this paper.

\subsection{Latent class path model formulation}

Basically, the latent class path model is a path model with mixture latent structures where a latent categorical variable is incorporated to capture the unobserved heterogeneity. It assumes that a certain number of latent classes result in the conditional independence of different outcomes. By keeping the homogeneity within each class, the interdependency relationships between variables across classes are different.

The latent class path model proposed here differs from the general path analysis which has become increasingly more popular in residential studies in the sense that the LCP model extends the modelling framework by allowing further decomposition of the complicated relationships between multiple variables. It allows the simultaneous estimation of a separate set of parameters for each class instead of the averaged effects in traditional path analysis, in order to identify unobserved variation. The model can be treated as a member of the general finite mixture model. More details about the general mixture model can be found in Muthén [53].

Assume there are $C$ latent classes. Then, the overall probability of individual $i$ having the intention to move house $y, P_{i}(y)$, is the summed product of the probability of moving intention of individual $i$ given latent class $c\left(c_{i}=1,2, \ldots, C\right), P\left(y \mid c_{i}=c\right)$, and the probability of individual $i$ belonging to certain class $c$ giving influential variable $z_{i}$, namely $P\left(c_{i}=c \mid z_{i}\right)$ [54]. Thus, the unconditional probability of individual $i$ having the intention to move house is:

$P_{i}(y)=\sum_{c=1}^{C} P\left(c_{i}=c \mid z_{i}\right) \cdot P\left(y \mid c_{i}=c\right)$

where $y$ is the categorical dependent variable and $z_{i}$ is a vector of the socio-demographic information of individuals and/or households.

The class membership that an individual $i$ belongs to class $c$ is considered a function of social demographics of individual $i$, which can be formulated through a multinomial logistic function:

$P\left(c_{i}=c \mid z_{i}\right)=\frac{e^{\boldsymbol{\alpha}_{c}+\gamma_{c} z_{i}}}{\sum_{c=1}^{C} e^{\boldsymbol{\alpha}_{c}+\gamma_{c} z_{i}}}$

where $\gamma_{c}$ is a vector of slope parameters and $\boldsymbol{\alpha}_{c}$ is the intercept.

Because latent class path models are composed of both a latent class specification and a path analysis specification, it can estimate the direct and indirect causal relationships and, at the same time, identify heterogeneity between individuals. The path model in this paper is composed of linear regression and binary logit models. Following the majority of prior studies, residential satisfaction is measured as interval scales $[49,55,56]$, while intention to move house is considered to be a nominal dependent variable $[57,58]$. Specifically, the intention to move house in this paper is treated as a binary variable, referring to intention to move or not move. The linear regression in the path model explains the causal relationship between residential gap and residential satisfaction while the binary logit model represents the influence of residential satisfaction on the intention to move house.

Based on the structural dependency presented in Fig. 1, within each class $c$, the relationship between satisfaction and residential gap is assumed to be linear: $s_{i n}=\theta_{0 c}+\sum_{m=1}^{M} \theta_{c m} g_{i m}+\varepsilon_{n}$

where $s_{i n}$ is the satisfaction of individual $i$ on dimension $n(n=1,2, \ldots$, $N)$. $g_{i m}$ is the residential gap of individual $i$ for attribute $m . \theta_{0 c}$ and $\theta_{c m}$ are parameters to be estimated. $\varepsilon_{n}$ is a normally distributed error term.

As the dependent variable "intention to move house" is categorical, the probability of the intention to stay $\left(y_{i}=0\right)$ and the intention to move $\left(y_{i}=1\right)$ of individual $i$ in each class can be expressed using a dichotomous probability function:

$P_{i}\left(y \mid c_{i}=c\right)= \begin{cases}\frac{1}{1+\mathrm{e}^{\beta_{0 c}+\sum_{n=1}^{N} \beta_{c n} s_{i n}}} & , y_{i}=0 \\ \frac{1}{1+\mathrm{e}^{-\left(\beta_{0 c}+\sum_{n=1}^{N} \beta_{c n} s_{i n}\right)}} & , y_{i}=1\end{cases}$

Here, $P_{i}\left(y \mid c_{i}=c\right)$ refers to the probability of intention to move house for individual $i$ given class $c$. $\beta_{0 c}$ and $\beta_{c n}$ are parameters to be estimated.

To estimate the LCP model, a maximum-likelihood estimation procedure involving the Expectation-Maximization (EM) algorithm was used. The EM algorithm is especially suitable for estimation problems that involve latent variables or missing data [59]. In general, the EM algorithm implements an iterative and transition calculation between the steps of expectation (E) and maximization (M) until the convergence condition is reached.

In the LCP model presented in Fig. 1, the expectation of the complete log-likelihood depends on all observed variables in the path model. Thus, it can be expressed by a posterior probability using Bayesian theory [60]:

$P_{i c}=P\left(c_{i}=c \mid \boldsymbol{y}_{i}, \boldsymbol{s}_{i}, \boldsymbol{g}_{i}, z_{i}\right)=\frac{P\left(c_{i}=c \mid z_{i}\right) P\left(\boldsymbol{s}_{i} \mid \boldsymbol{c}_{i}, \boldsymbol{g}_{i}\right) P\left(\boldsymbol{y}_{i} \mid \boldsymbol{c}_{i}, \boldsymbol{s}_{i}\right)}{P\left(\boldsymbol{y}_{i}, \boldsymbol{s}_{i} \mid \boldsymbol{g}_{i}\right)}$

where $P_{i c}$ refers to the posterior probability of individual $i$ belonging to class $c$ [61].

Because of the inherent dependency between variables of $\boldsymbol{y}, \boldsymbol{s}, \boldsymbol{g}$ in the path model, the latent class $c$ and social-demographics $(\boldsymbol{z})$, the expectation is based on the relationships between all variables, including the relationship between $c$ and $z, s$ and $c, g, y$ and $c, s$. Considering the mechanism of the EM algorithm, the expectation of log likelihood should be the sum of all the interdependencies within the path model $[62,63]$. Therefore, the expectation of the log likelihood is the expectation of the sum of following three log likelihood functions:

$E\left\{\log L\left(c_{i}=c \mid z_{i}\right)+\log L\left(\boldsymbol{s}_{i} \mid \boldsymbol{c}_{i}, \boldsymbol{g}_{i}\right)+\log L\left(\boldsymbol{y}_{i} \mid \boldsymbol{c}_{i}, \boldsymbol{s}_{i}\right)\right\}$

Using probability expression, equation (7) becomes:

$E\left\{\log \prod_{i=1}^{I} P\left(c_{i}=c \mid z_{i}\right)+\log \prod_{i=1}^{I} P\left(\boldsymbol{s}_{i} \mid \boldsymbol{c}_{i}, \boldsymbol{g}_{i}\right)+\log \prod_{i=1}^{I} P\left(\boldsymbol{y}_{i} \mid \boldsymbol{c}_{i}, \boldsymbol{s}_{i}\right)\right\}$

$=E\left\{\sum_{i=1}^{I} \log P\left(c_{i}=c \mid z_{i}\right)+\sum_{i=1}^{I} \log P\left(\boldsymbol{s}_{i} \mid \boldsymbol{c}_{i}, \boldsymbol{g}_{i}\right)+\sum_{i=1}^{I} \log P\left(\boldsymbol{y}_{i} \mid \boldsymbol{c}_{i}, \boldsymbol{s}_{i}\right)\right\}$

$=E\left\{\sum_{i=1}^{I}\left[\log P\left(c_{i}=c \mid z_{i}\right)+\log P\left(\boldsymbol{s}_{i} \mid \boldsymbol{c}_{i}, \boldsymbol{g}_{i}\right)+\log P\left(\boldsymbol{y}_{i} \mid \boldsymbol{c}_{i}, \boldsymbol{s}_{i}\right)\right]\right\}$

Because the expectation of the sum of three relations in Equation (8) is equivalent to the sum of the expectation of each element, we can address the expectation of each element separately. For $c$ related to $z$, the maximization of expectation is:

$E\left\{\sum_{i=1}^{I}\left[\log P\left(c_{i}=c \mid z_{i}\right)\right]\right\}=\sum_{i=1}^{I} \sum_{c=1}^{C} P_{i c} \log P\left(c_{i}=c \mid z_{i}\right)$

Given that $s$ is a continuous variable, the maximization for $s$ related to $c, g$ is: 

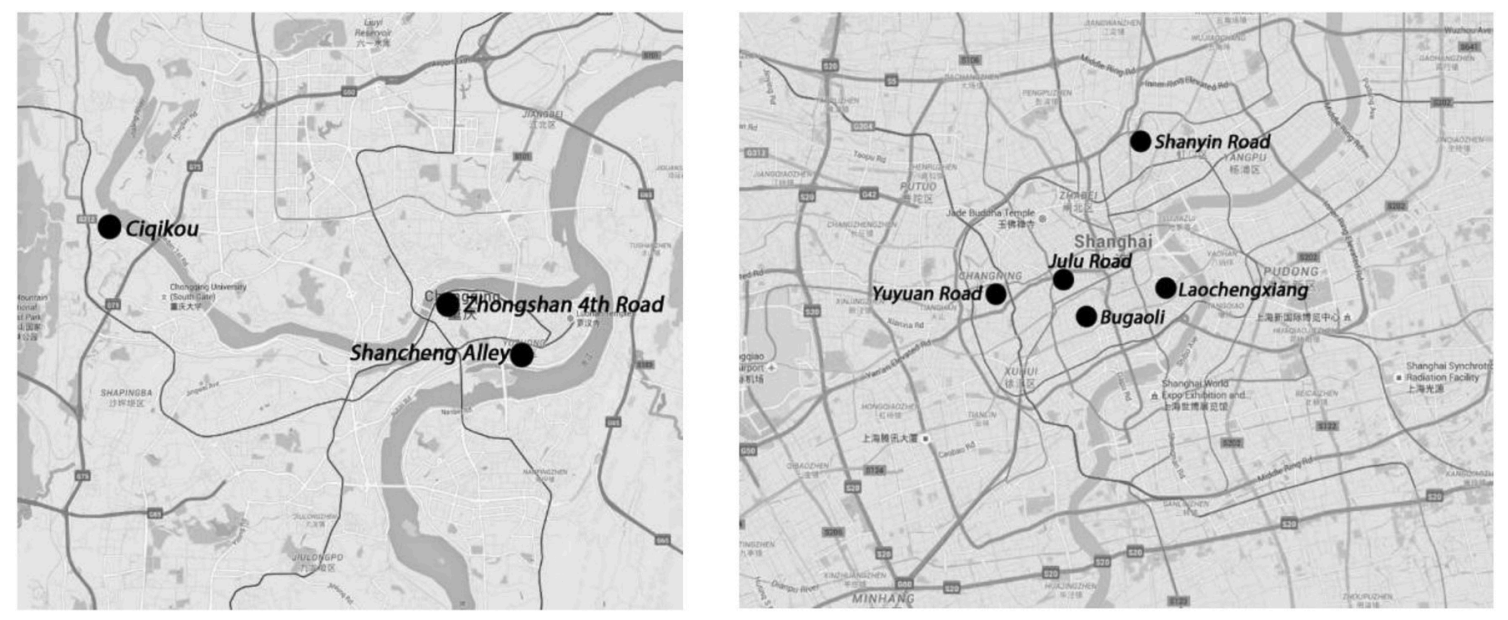

Fig. 2. The location of historical blocks (three in Chongqing and five in Shanghai).

$$
\begin{aligned}
E\left\{\sum_{i=1}^{I}\left[\log P\left(\boldsymbol{s}_{i} \mid \boldsymbol{c}_{i}, \boldsymbol{g}_{i}\right)\right]\right\}= & E\left\{\sum_{i=1}^{I} \sum_{c=1}^{C} c_{i} \log P\left(\boldsymbol{s}_{i} \mid \boldsymbol{g}_{i}\right)\right\} \\
& =\sum_{i=1}^{I} \sum_{c=1}^{C} P_{i c} \log P\left(\boldsymbol{s}_{i} \mid \boldsymbol{g}_{i}\right)_{c}
\end{aligned}
$$

Given that $y$ is a categorical variable, the maximization of expectation for $y$ related to $c, s$ is:

$$
E\left\{\sum_{i=1}^{I}\left[\log P\left(\boldsymbol{y}_{i} \mid \boldsymbol{c}_{i}, \boldsymbol{s}_{i}\right)\right]\right\}=\sum_{i=1}^{I} \sum_{c=1}^{C} P_{i c}\left[\log P\left(y_{i}=0 \mid \boldsymbol{c}_{i}, \boldsymbol{s}_{i}\right)+\log P\left(y_{i}=1 \mid \boldsymbol{c}_{i}, \boldsymbol{s}_{i}\right)\right]
$$

\section{Data collection}

The data used in this paper was collected in renovated Chinese historical blocks. Historical blocks in China are of special interest in residential studies because they offer a natural setting to examine the influence of residential gap on residential mobility as they have experienced several rounds of renovation. One may assume that renovations bring perceived reality closer to aspirations. Yet, the perceived reality may fluctuate during different stages of the renovation process, generating variability in residential gap and satisfaction. Furthermore, both positive and negative situations in these historical blocks may influence residents' opinions about aspiration and satisfaction during the renovation process. In general, houses in historical blocks have a higher cultural value but tend to be in a worse condition. Compared with other urban areas, the high rent and house price resulted from their central location increases the ambivalence of residents that aspire both a better living environment and good location. Moreover, residents are facing more constraints, such as a lower percentage of ownership. The lower education degree and income imply they may be less able to act on their preferences and think differently about residential mobility. Overall, for these reasons, Chinese historical blocks offer interesting and highly relevant data to comprehensively understand the direct and indirect relationships defined within the framework.

The data was collected from eight historical blocks in two selected Chinese cities, Chongqing and Shanghai. In order to get a more general sample to represent the Chinese context rather than specific data from one city, two cities, one from the western China (Chongqing) and another from the eastern (Shanghai), are chosen as the empirical field. Both cities are first-tier cities (i.e. displaying strong political and economic influence within China). Both cities have a long history and several historical areas. Currently, fourteen historical areas exist in Shanghai, while eight remains in Chongqing. The number of historical blocks chosen from each city is proportional to the number of their remaining historical areas. To be representative, three historical blocks from Chongqing and five from Shanghai were randomly chosen in the survey.

All eight historical blocks are located in city centres, having good transportation connections. The size of historical blocks varies from 0.1 to $0.5 \mathrm{~km}^{2}$ in Chongqing, and from 0.03 to $0.15 \mathrm{~km}^{2}$ in Shanghai. Their population size is between 2000 and 14000 inhabitants. All blocks have experienced different levels of renovation, which can be classified into three stages. Specifically, Shancheng alley (Chongqing) and Laochengxiang (Shanghai) are at the early renovation stage in which few rounds of small renovation occurred and few inhabitants moved out. Ciqikou (Chongqing), Julu Road, Shanyin Road and Yuyuan Road blocks (Shanghai) are experiencing the middle stage of renovation in which at least one huge scale of renovation took place and part of local residents were displaced. Zhongshan 4th Road and Bugaoli are at the late renovation stage because they experienced several rounds of major renewal and a large proportion of local residents have moved out (Fig. 2).

The questionnaire includes several residential dimensions structured according to Clark and Onaka [48]. In order to keep consistency with our conceptual framework, only data from housing and living environmental dimensions are used for this analysis. The housing dimension consists of four variables, e.g. size, non-shared kitchen and bathroom, technical quality and repair support, while the living environmental dimension includes distance to the shopping mall, good road condition, gas pipe, small community park and walkability.

To measure the aspiration and reality, each variable was measured from both the aspects of desired situation (aspiration) and current perceived situation (reality). In case of continuous attributes, respondents were asked to specify the detailed specific value of aspiration and reality related to the specific information. For categorical attributes, respondents were asked to choose among the options provided. To measure the residential satisfaction, at the end of every dimension, an overall satisfaction level was measured on a seven-point scale, from "extremely unsatisfied" to "extremely satisfied". At the end of the questionnaire, the mobility intention was recorded also on the sevenpoint scale, from "extremely do not want to move" to "extremely want to move", giving the time limit of coming five years [12].

The data collection lasts from April to June 2015. Questionnaires were distributed underlying random sampling method so that 50 respondents from each block were randomly selected. Considering the relatively high age and low education level of local residents, the survey was conducted on a face-to-face basis. Ultimately, 384 questionnaires were finished with the help of local authorities, which leads to a response rate of $96 \%$. This high response rate is also due to the fact that 
Table 1

Description of mobility and social-demographic data.

\begin{tabular}{|c|c|c|c|c|}
\hline Variable type & Variable & Category & $\mathrm{N}$ & $\begin{array}{l}\text { Frequency } \\
(\%)\end{array}$ \\
\hline \multirow[t]{2}{*}{ Mobility data } & Intention to & Move & 167 & 44.5 \\
\hline & Move House & Stay & 208 & 55.5 \\
\hline \multirow{13}{*}{$\begin{array}{l}\text { Social- } \\
\text { demographic } \\
\text { data }\end{array}$} & Gender & Male & 184 & 49.1 \\
\hline & & Female & 191 & 50.9 \\
\hline & Supporting & Yes & 139 & 37.1 \\
\hline & elderly & No & 236 & 62.9 \\
\hline & Education Level & $\begin{array}{l}\text { Junior high school } \\
\text { and under }\end{array}$ & 169 & 45.1 \\
\hline & & Senior high school & 130 & 34.7 \\
\hline & & $\begin{array}{l}\text { Junior college and } \\
\text { over }\end{array}$ & 76 & 20.3 \\
\hline & Tenure & Rent & 213 & 56.8 \\
\hline & & $\begin{array}{l}\text { Shared rights with } \\
\text { government }\end{array}$ & 9 & 2.4 \\
\hline & & Bought & 153 & 40.8 \\
\hline & $\begin{array}{l}\text { Renovation } \\
\text { Stage }\end{array}$ & $\begin{array}{l}\text { Early stage of } \\
\text { renovation }\end{array}$ & 96 & 25.6 \\
\hline & & $\begin{array}{l}\text { Middle stage of } \\
\text { renovation }\end{array}$ & 192 & 51.2 \\
\hline & & $\begin{array}{l}\text { Late stage of } \\
\text { renovation }\end{array}$ & 87 & 23.2 \\
\hline
\end{tabular}

most residents are willing to express their preferences in the hope of better historical blocks renovations. In addition, the assistance by community members during the introduction to the respondents also helps saving some survey efforts and increases the participation rate. As one question contains missing data, only 375 questionnaires were used in this analysis.

The sample statistics are shown in Table 1 . The total number of samples is 375 . After merging the four scales from "extremely do not want to move" to "neutral" and merging the three scales from "a little want to move" to "extremely want to move", the variable intention to move house was classified into binary categories, "intention to stay" and "intention to move", it is found that over half of the respondents has the intention to stay, while $44.5 \%$ would like to move. The statistics of residential gap and satisfaction indicate some variance exists between residents. Females and males are almost equally distributed $(49.1 \%$ vs. $50.1 \%$ for male and female) and $37.1 \%$ of the families need to support the elderly. Local residents have relatively low education level that $79.8 \%$ of them possesses education level of senior high school and lower, including $45.1 \%$ having a degree lower than junior high school and $34.7 \%$ with senior high school degree. $56.8 \%$ of families are renting houses, while $40.8 \%$ own a house. The left $2.4 \%$ share property rights with government. Regarding the renovation stages, half of the respondents are living in the historical blocks experiencing middle stage of renovation $(51.2 \%)$ (Table 1$)$. Table 2 shows the statistical description of reality, aspiration, residential satisfaction of every dimension and the residential gap. On average, residents expressed lower satisfaction on the housing dimension compared to the environmental dimension. House sizes in these blocks are relatively small and residents' perceptions of the house quality are relatively low.

\section{Results}

This section presents the results of the latent class path model that was estimated using Mplus. The multicollinearity of variables was tested by calculating the variance inflation factor (VIF). Results of all VIF tests range from 1.021 to 1.402 , which means that no serious multicollinearity exists between variables. Normality was tested using Kolmogorov-Smirnova and Shapiro-Wilk test. Results were insignificant with a p-value higher than 0.05 . Because determining the optimal number of classes is important in latent class analysis, models with two, three and more classes were tested. Given that LCP model has a different estimation mechanism compared to the average path model, a dedicated set of fitting criteria has been adopted [60,64-66]. Results are shown in Table 3. Comparing all criteria, despite the same BLRT (Bootstrap likelihood ratio test), the model with two classes has a lower Bayesian Information Criterion (BIC), lower Vuong-Lo-Mendell-Rubin test (VLMR) and a higher entropy, higher Akaike's Information Criterion (AIC). As

Table 3

Comparison of results between different classes.

\begin{tabular}{llllll}
\hline Number of class & AIC & BIC & Entropy & VLMR & BLRT \\
\hline 2 classes & 2390.362 & 2551.366 & 0.810 & 0.09 & 0.00 \\
3 classes & 2342.733 & 2597.983 & 0.759 & 0.43 & 0.00 \\
4 classes & 2355.233 & 2663.360 & 0.716 & 0.60 & 0.66 \\
\hline
\end{tabular}

Table 2

Description of reality, aspiration, residential gap and residential satisfaction.

\begin{tabular}{|c|c|c|c|c|c|c|c|c|}
\hline & \multirow[t]{2}{*}{$\begin{array}{l}\text { Residential satisfaction } \\
\text { of this dimension }\end{array}$} & \multirow[t]{2}{*}{$\begin{array}{l}\text { Variable of this } \\
\text { dimension }\end{array}$} & \multirow[t]{2}{*}{$\begin{array}{l}\text { Category (if } \\
\text { categorical data) }\end{array}$} & \multirow[t]{2}{*}{ Reality } & \multirow[t]{2}{*}{ Aspiration } & \multirow[t]{2}{*}{$\begin{array}{l}\text { Residential gap } \\
\text { (continuous) }\end{array}$} & \multicolumn{2}{|c|}{$\begin{array}{l}\text { Residential gap } \\
\text { (categorical) }\end{array}$} \\
\hline & & & & & & & Mismatch & Match \\
\hline \multirow[t]{9}{*}{ Housing dimension } & $3.910(1.238)$ & Size $\left(\mathrm{m}^{2}\right)$ & & $\begin{array}{l}38.16 \\
(25.18)\end{array}$ & $\begin{array}{l}66.08 \\
(29.11)\end{array}$ & $0.60(0.28)$ & & \\
\hline & & Technical Quality & & $3.56(1.47)$ & $7.00(0.00)$ & $0.47(0.25)$ & & \\
\hline & & Non-shared Kitchen & Having both & $52.0 \%$ & $97.3 \%$ & & $47.1 \%$ & $52.9 \%$ \\
\hline & & \& Bathroom & Only bathroom & $17.6 \%$ & $1.3 \%$ & & & \\
\hline & & & Only kitchen & $5.1 \%$ & $1.3 \%$ & & & \\
\hline & & & Neither & $25.3 \%$ & $0 \%$ & & & \\
\hline & & Repairing Support & Yes & $60.8 \%$ & $81.3 \%$ & & $34.6 \%$ & $65.4 \%$ \\
\hline & & & No & $29.3 \%$ & $5.9 \%$ & & & \\
\hline & & & Not sure & $9.9 \%$ & $12.8 \%$ & & & \\
\hline \multirow{9}{*}{$\begin{array}{l}\text { Environmental } \\
\text { dimension }\end{array}$} & $4.380(1.087)$ & Walkability & & $4.61(1.02)$ & $7.00(0.00)$ & $0.65(0.14)$ & & \\
\hline & & Distance to the Mall & & 1594.99 & 1052.14 & $0.55(0.45)$ & & \\
\hline & & $(\mathrm{m})$ & & $(927.48)$ & $(651.61)$ & & & \\
\hline & & Small Community & & $5.39(1.48)$ & $6.50(1.42)$ & $0.70(0.30)$ & & \\
\hline & & Park & & & & & & \\
\hline & & Good Road condition & Yes & $79.5 \%$ & $100 \%$ & & $20.5 \%$ & $79.5 \%$ \\
\hline & & & No & $20.5 \%$ & $0 \%$ & & & \\
\hline & & Gas Pipe & Yes & $78.1 \%$ & $100 \%$ & & $21.9 \%$ & $78.1 \%$ \\
\hline & & & No & $21.9 \%$ & $0 \%$ & & & \\
\hline
\end{tabular}

Note: 1 . The numbers outside the parentheses are mean, while numbers in the parentheses are standard deviation.

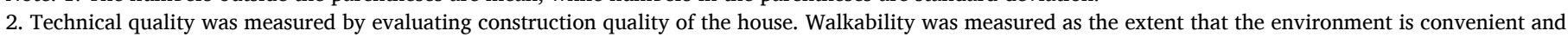

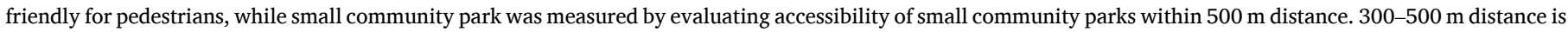
regulated by the code for urban residential areas planning and design in China, 2018. 

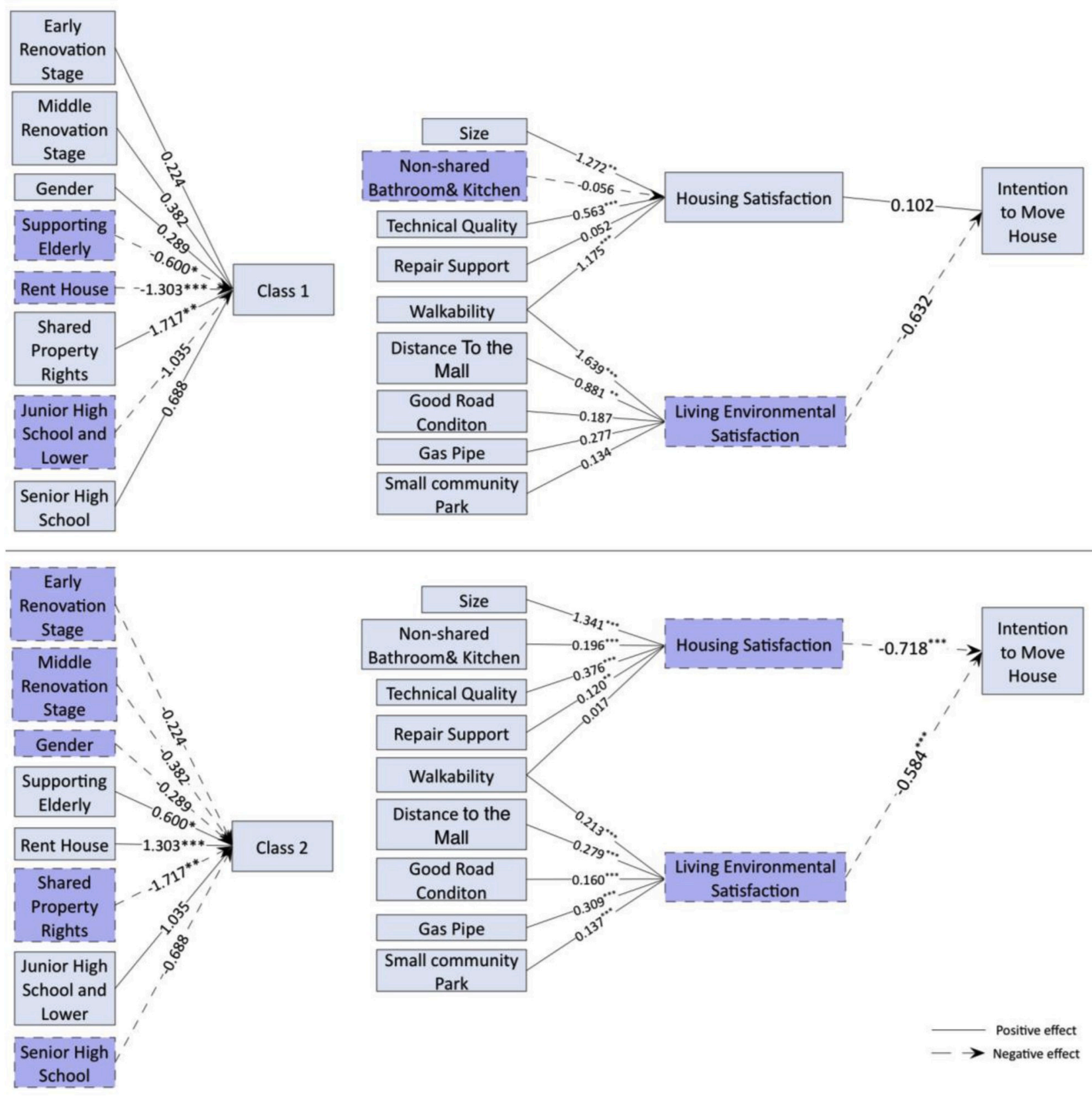

Fig. 3. Results of latent class path model.

Nylund et al. [64] indicated that AIC may not be a good indicator for class enumeration in latent class analysis (LCA) with categorical outcomes, while BIC normally performs better in an LCA Monte Carlo study than AIC, BIC is a more reliable criteria to determine the optimal number of classes. The VLMR is significant for the two-class model and insignificant for the three-class and four-class model, which suggests that the two-class model is better than the single class model and two classes are already sufficient so that three or more classes are not needed. As an important criterion in LCA, entropy evaluates the quality of each class that is represented by the data. Empirically, entropy over 0.8 is preferred [67]. Therefore, with a higher entropy and lower BIC and VLMR, the model with two classes is adopted (Table 3) (Fig. 3).

The results of the two-class path model are shown in Fig. 3. Considering the important relevance of other key variables and our assumption in explaining the intention to move illustrated in the conceptual framework, some insignificant parameters are also retained in the model. It is found that the impacts of housing and living environmental satisfaction on the intention to move house are significant in class 2 and insignificant in class 1, indicating that moving intention of respondents in class 1 , are not influenced by neither housing nor living environmental satisfaction, but by other factors. The housing satisfaction in class $2(-0.718)$ has a bigger influence on the intention to move house than living environmental satisfaction $(-0.584)$. The negative signs indicate that lower housing satisfaction or living environmental satisfaction will lead to higher intention to move house, which is as expected.

In both classes, all residential gap indices have positive impacts on residential satisfaction except for the one that is insignificant (nonshared bathroom and kitchen in class 1 ), which coincides with the assumption that residents feel more satisfied when reality approaches their aspiration. The smaller the gap index, the larger the gap and the lower the residential satisfaction. In class 1 , the gap index for house size 
Table 4

Class profiling of every class.

\begin{tabular}{|c|c|c|c|c|c|}
\hline Variable type & & Variable & & Class 1 & Class 2 \\
\hline \multirow[t]{2}{*}{ Residential Satisfaction } & & Housing Satisfaction & & $4.04(1.91)$ & $3.89(1.12)$ \\
\hline & & Living Environmental Satisfaction & & $4.49(2.04)$ & $4.36(0.89)$ \\
\hline \multirow[t]{6}{*}{ Residential Gap (Housing dimension) } & Continuous & Size & & $0.58(0.25)$ & $0.60(0.28)$ \\
\hline & & Technical quality & & $0.49(0.23)$ & $0.47(0.25)$ \\
\hline & Categorical & Non-shared Kitchen \&Bathroom & Mismatch & $43.9 \%$ & $47.0 \%$ \\
\hline & & & Match & $56.1 \%$ & $53.0 \%$ \\
\hline & & Repairing Support & Mismatch & $34.1 \%$ & $35.3 \%$ \\
\hline & & & Match & $65.9 \%$ & $64.7 \%$ \\
\hline \multirow[t]{7}{*}{ Residential Gap (Environmental dimension) } & Continuous & Walkability & & $0.70(0.16)$ & $0.65(0.14)$ \\
\hline & & Distance to the Mall & & $0.60(0.45)$ & $0.55(0.46)$ \\
\hline & & Small Community Park & & $0.69(0.32)$ & $0.71(0.30)$ \\
\hline & Categorical & Good Road Condition & Mismatch & $19.5 \%$ & $20.7 \%$ \\
\hline & & & Match & $80.5 \%$ & $79.3 \%$ \\
\hline & & Gas Pipe & Mismatch & $17.1 \%$ & $22.5 \%$ \\
\hline & & & Match & $82.9 \%$ & $77.5 \%$ \\
\hline \multirow[t]{13}{*}{ Socio-demographics } & & Early Renovation Stage & & $26.8 \%$ & $25.4 \%$ \\
\hline & & Middle Renovation Stage & & $65.9 \%$ & $49.4 \%$ \\
\hline & & Late Renovation Stage & & $7.3 \%$ & $25.1 \%$ \\
\hline & & Male & & $41.5 \%$ & $50.0 \%$ \\
\hline & & Female & & $58.5 \%$ & $50.0 \%$ \\
\hline & & Elderly & & $22.0 \%$ & $38.9 \%$ \\
\hline & & No Elderly & & $78.0 \%$ & $61.1 \%$ \\
\hline & & Rent House & & $34.1 \%$ & $59.6 \%$ \\
\hline & & Shared Property Rights & & $14.6 \%$ & $0.9 \%$ \\
\hline & & Own House & & $51.2 \%$ & $39.5 \%$ \\
\hline & & Junior High School and Under & & $12.2 \%$ & $49.1 \%$ \\
\hline & & Senior High School & & $61.0 \%$ & $31.4 \%$ \\
\hline & & Junior College and Over & & $26.8 \%$ & $19.5 \%$ \\
\hline
\end{tabular}

Note: The numbers outside the parentheses are mean, while numbers in the parentheses are standard deviation.

(1.272) influences residents' housing satisfaction the most, followed by the gap index for technical quality (0.563) and walkability (1.175). This means the residential satisfaction for residents in class 1 is mainly influenced by the house size. In case of the satisfaction on environment, only the coefficients of walkability (1.639) and distance to the shopping mall $(0.881)$ are statistically significant, in which the effect of walkability is almost doubled relative to that of distance to the shopping mall. This indicates that the living environment with better walkability can significantly increase people's satisfaction. It should be noted that the gap index of walkability has a significant effect on both housing and residential satisfaction in class 1 .

In class 2, all gap variables except for walkability exert significant and positive effects on housing satisfaction, which means lower gap will increase the residential satisfaction. Among all gap indices, the house size is again the most influential variable, while the repair support from government is the least important variable. Not like the residents in class 1 who consider only walkability and distance to the shopping mall important, all gap indices in the dimension of living environmental

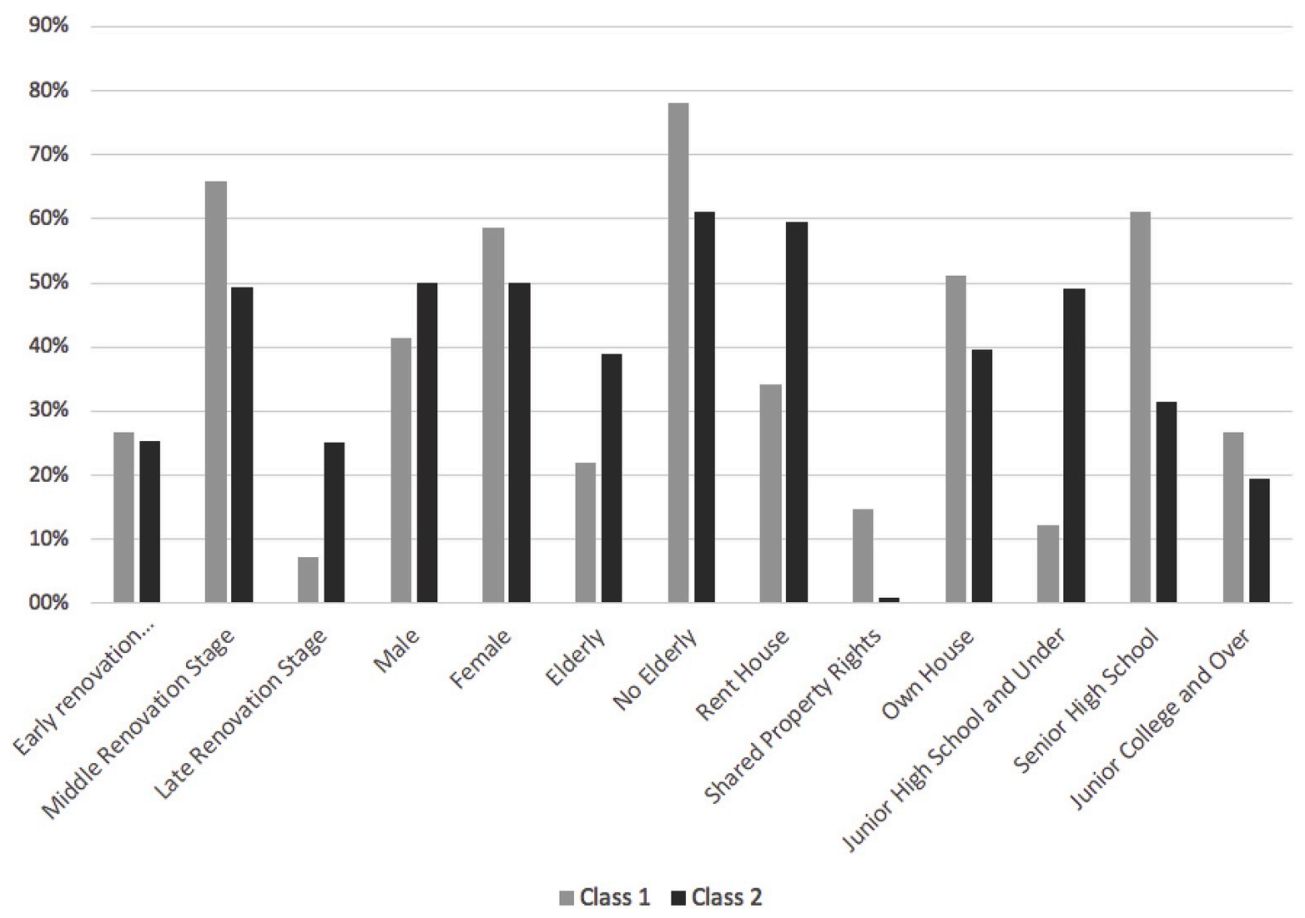

Fig. 4. Class profiling of socio-demographic characteristics. 
satisfaction are significant in class 2 , which means residents in class 2 also care about other aspects regarding facilities and infrastructures, i.e., good road condition, gas pipe and small community park.

To better understand class differences, class membership is estimated as a function of social-demographic information. Results show that the estimates of supporting elderly, rent house and shared property rights are statistically significant. The coefficient of shared property rights and renting house equal to 1.717 and -1.303 for class 1 , which means that people who have shared property rights and not renting house are more likely to belong to latent class 1 , while people who rent houses are more likely to belong to class 2 . The coefficient of supporting elderly is negative $(-0.600)$ for class 1 , which indicates that the probability that residents supporting elderly belong to class 2 is higher than the probability they belong to class 1 . Note that the probability that respondents belong to class 1 is $11 \%$, while the probability is $89 \%$ when they belong to class 2 .

In order to further examine the residential gap, satisfaction and social demographic features of individuals in each class, results of class profiling are presented in Table 4 and Fig. 4. It is shown the residents in class 1 on average express better residential satisfaction compared to those in class 2. Different classes have varying residential gap regarding housing and living environmental attributes. The detailed profiling of social demographics is expected to provide useful references for planning interventions.

\section{Conclusions and discussion}

Although a large number of studies have enriched our knowledge about residential mobility, it seems that the unobserved heterogeneity between different groups of residents underlying integrated models has not been addressed yet. Therefore, this paper proposes a latent class path model to explore the differences in residential decision structure, depicted in the direct and indirect interdependencies between intention to move house, residential satisfaction regarding the house and living environment and residential gap, in which residential satisfaction is viewed as a function of the discrepancy between aspiration and perceived reality. The model specifies class membership as a function of social-demographic characteristics. Using data collected from eight historical blocks in two selected Chinese cities, the proposed latent class path model was estimated. As demonstrated, the model is capable of identifying heterogeneity and interdependency between different variables in a comprehensive way.

Results show that a clear difference exists between two groups of residents in moving intention when taking into account the level of aspiration and residential satisfaction. The intention to move house is significantly influenced by housing and living environmental satisfaction for residents in class 2 , but not in class 1 . Residents in class 1 generally have higher housing and living environmental satisfaction. For residents in class 1 , their moving intention may be influenced by residential satisfaction of other dimensions that is not considered in this study. Being consistent with residential studies in other urban areas (e. g., $[9,28]$ ), housing satisfaction was found the most influential for moving intention. Compared with the residents in class 2 who tend to consider most residential gaps important, the housing satisfaction of residents in class 1 is only influenced significantly by gap index of house size, technical quality and walkability (influence of governmental repair support and non-shared kitchen and bathroom are insignificant). The gap ratio regarding house size is the most important indicator for residents in both classes. Even though the parameter of house size is also found significant in studies for other urban areas [68,69], it is regarded as the most significant one in historical blocks because the small house size in these blocks is a large constraint for residents. Moreover, the residential gaps show different effects on living environmental satisfaction between the two classes. Compared with residents in class 1 whose living environmental satisfaction is only significantly influenced by walkability and distance to the shopping mall, respondents in class 2 also consider good road conditions, gas pipe and small community park important.

Results of the membership estimation show that on average people who rent a house and need to support elderly are more likely to belong to class 2 , while people who have shared property rights and are not bounded to support elderly are more likely to belong to class 1 .

Results of this analysis can provide detailed renovation suggestions considering the interests of different groups of Chinese residents. First, as a large group of residents need to support the elderly and they consider road condition and community parks important, better road and more small parks should be considered in future renovations. Second, for a large proportion of individuals who live in these blocks as renters, offering better facilities like gas pipes or non-shared bathroom and kitchen would increase their residential satisfaction. Third, more governmental repairing support should be provided for houses, especially on improving housing technical quality, since a large proportion of residents consider housing more important compared to living environment while forming the moving intention.

Comparing these findings related to the Chinese context with earlier research work in the literature pertaining to a non-Chinese context, we can argue that at an aggregate level housing preferences seem rather similar across the world and certain international policy implications can be drawn based on the findings. Attributes about the house seem more important in explaining residential preferences and moving intention and the environment amenities is less important. A possible explanation for this finding is that people spend most time and therefore derive most utility from their house. Thus, improving housing conditions should be primarily considered by the policy makers globally during renovations. Secondly, ownership and other social-demographic backgrounds constrain and classify people while forming their residential preferences in the renovated areas in China, this is in line with findings of other studies in different environments. Thus, understanding residential needs and later providing related supports for different groups of people with varying constrained backgrounds could be considered by policy makers in renovations worldwide.

Although the data used was from the historical blocks in China, the proposed latent class path approach is generalizable in non-Chinese contexts. When applying this model in other areas, one may not rule out the unique features of a particular context. It would be natural that the classification results differ between different contexts, which leads to richer understanding in residential satisfaction and housing domain. Especially, when local authorities want to understand better the preferences of different groups of residents from a particular aspect, these unique features from different contexts can be incorporated well in the proposed modelling approach.

\section{Declaration of competing interest}

None.

\section{Acknowledgements}

The Fundamental Research Funds for the Central Universities (No. 2019CDXYJZ0025) and Fund for the Key Laboratory of New Technology for Construction of Cities in Mountain Area (No. LNTCCMA-20200110).

\section{Appendix A. Supplementary data}

Supplementary data to this article can be found online at https://doi. org/10.1016/j.seps.2019.100743.

\section{References}

[1] Kwon HJ, Beamish JO. Older adults in multifamily housing: residential satisfaction and intention to move. Fam Consum Sci Res J 2013;42(1):40-54. https://doi.org $/ 10.1111 /$ fcsr. 12037. 
[2] Kim H, Woosnam KM, Marcouiller DW, Aleshinloye KD, Choi Y. Residential mobility, urban preference, and human settlement: a South Korean case study. Habitat Int 2015;49:497-507. https://doi.org/10.1016/j.habitatint.2015.07.003.

[3] Earhart CC, Weber MJ. Attachment-to-home: a contributing factor to models of residential mobility intentions. Fam Consum Sci Res J 1996. https://doi.org/10. $1177 / 1077727$ X 960244007.

[4] Clark WAV, Huang Y. The life course and residential mobility in British housing markets. Environ Plan 2003;35(2):323-39. https://doi.org/10.1068/a3542.

[5] Huang Y, Deng FF. Residential mobility in Chinese cities: a longitudinal analysis. Hous Stud 2006;21(5):625-52. https://doi.org/10.1080/02673030600807084.

[6] Varady DP. Housing problems and mobility plans among the elderly. J Am Plan Assoc 1980;46(3):301-14. https://doi.org/10.1080/01944368008977045.

[7] Diaz-Serrano L, Stoyanova AP. Mobility and housing satisfaction: an empirical analysis for 12 EU countries. J Econ Geogr 2010;10(5):661-83. https://doi.org 10.1093/jeg/lbp045.

[8] Diaz-Serrano L. Disentangling the housing satisfaction puzzle: does homeownership really matter? J Econ Psychol 2009;30(5):745-55. https://doi. org/10.1016/j.joep.2009.06.006.

[9] Ren H, Folmer H. Determinants of residential satisfaction in urban China: a multigroup structural equation analysis. Urban Stud 2016;54(6):1407-25. https://doi. org/10.1177/0042098015627112.

[10] Clark WAV. Recent research on migration and mobility: a review and interpretation. Prog Plan 1982;18:1-56. https://doi.org/10.1016/0305-9006(82) 90002-2.

[11] Galster G. Identifying the correlates of dwelling satisfaction:an empirical critique Environ Behav 1987;19(5):539-68.

[12] Oh J. Social bonds and the migration intentions of elderly urban residents: the mediating effect of residential satisfaction. Popul Res Policy Rev 2003;22(2): $127-46$.

[13] Rabe B, Taylor M. Residential mobility, quality of neighbourhood and life course events. J R Stat Soc Ser A Stat Soc 2010;173(3):531-55. https://doi.org/10.1111/j 1467-985X.2009.00626.x.

[14] Dane GZ, Griglon AB, Rasouli S, Timmermans H. Determinants of residential mobility intentions: a mixed binary logit model. In: The 19th International Conference of Hong Kong Society for Transportation Studies. 12; 2014. p. 1-8 (13-15), https://doi.org/10.1017/CBO9781107415324.004.

[15] Speare JA, Goldstein S, Frey WH. Residential mobility, migration, and metropolitan change. Ballinger Pub. Co; 1975.

[16] Jansen SJT. The impact of the have-want discrepancy on residential satisfaction. J Environ Psychol 2014;40:26-38. https://doi.org/10.1016/j.jenvp.2014.04.006.

[17] Sulaiman H, Yahaya N. Housing provision and satisfaction of low-income households in Kuala Lumpur. Habitat Int 1987;11(4):27-38. https://doi. org/10.1016/0197-3975(87)90006-3.

[18] Tang Y. A study of housing aspiration and social interactions of China's generation Y. Chongqing university; 2012.

[19] Jiang W, Feng T, Timmermans H, Li H. A gap-theoretical path model of residential satisfaction and intention to move house applied to renovated historical blocks in two Chinese cities. Cities 2017;71(11):19-29. https://doi.org/10.1016/j.cities.20 17.06.021.

[20] Yang J, Wu M. Modern urban renewal. Nanjing: Southeast Univeristy Press; 1999.

[21] Ruan Y. Protect our root: city development and protection of culture heritages. Urban Rurual Dev 2004;7:8-11. https://doi.org/10.1017/CBO9781107415324 .004 .

[22] Wang J. The cities in the notebook. SDX Joint Publishing Company; 2008.

[23] Li SM, Song YL. Redevelopment, displacement, housing conditions, and residential satisfaction: a study of Shanghai. Environ Plan 2009;41(5):1090-108. https://doi. org/10.1068/a4168.

[24] Mohit MA, Ibrahim M, Rashid YR. Assessment of residential satisfaction in newly designed public low-cost housing in Kuala Lumpur, Malaysia. Habitat Int 2010;34 (1):18-27. https://doi.org/10.1016/j.habitatint.2009.04.002.

[25] Dekker K, de Vos S, Musterd S, van Kempen R. Residential satisfaction in housing estates in European cities: a multi-level research approach. Hous Stud 2011;26(4): 479-99. https://doi.org/10.1080/02673037.2011.559751.

[26] Oakley D, Ruel E, Reid L. Atlanta's last demolitions and relocations: the relationship between neighborhood characteristics and resident satisfaction. Hous Stud 2013;28(2):205-34. https://doi.org/10.1080/02673037.2013.767887.

[27] Posthumus H, Bolt G, Van Kempen R. Victims or victors? The effects of forced relocations on housing satisfaction in Dutch cities. J Urban Aff 2014;36(1):13-32 https://doi.org/10.1111/juaf.12011.

[28] Etminani-Ghasrodashti R, Majedi H, Paydar M. Assessment of residential satisfaction in mehr housing scheme: a case study of Sadra new town, Iran. Hous Theory Soc 2017;34(3):323-42. https://doi.org/10.1080/14036096.2017.1 298536.

[29] Campbell A, Converse PE, Rodgers WL. Satisfaction, aspirations, and expectations. Qual Am Life 1976;583.

[30] Böheim R, Taylor MP. Tied down or room to move? Investigating the relationships between housing tenure, employment status and residential mobility in Britain. Scott J Political Econ 2002;49(4):369-92. https://doi.org/10.1111/1467-9 485.00237.

[31] Lee BA, Oropesa RS, Kanan JW. Neighborhood context and residential mobility. Demography 1994;31(2):249-70. https://doi.org/10.2307/2061885.

[32] Kan K. Residential mobility and social capital. J Urban Econ 2007;61(3):436-57. https://doi.org/10.1016/j.jue.2006.07.005.

[33] Ren H, Folmer H, van der Vlist AJ. The impact of home ownership on life satisfaction in urban China: a propensity score matching analysis. J Happiness Stud 2016:1-26. https://doi.org/10.1007/s10902-016-9826-x.
[34] Burholt V. Testing a behavioural and a developmental model of migration: a reevaluation of migration patterns among the elderly and why older people move. Environ Plan 1999;31(11):2071-88. https://doi.org/10.1068/a312071.

[35] Ettema D. The impact of telecommuting on residential relocation and residential preferences. A latent class modeling. J Transp Land Use 2010;3(1):7-24. https:// doi.org/10.5198/jtlu.v3i1.61.

[36] Walker JL, Li J. Latent lifestyle preferences and household location decisions. J Geogr Syst 2007;9(1):77-101. https://doi.org/10.1007/s10109-006-0030-0.

[37] Olaru D, Smith B, Taplin JHE. Residential location and transit-oriented development in a new rail corridor. Transp Res A Policy Pract 2011;45(3):219-37. https://doi.org/10.1016/j.tra.2010.12.007.

[38] Smith B, Olaru D. Lifecycle stages and residential location choice in the presence of latent preference heterogeneity. Environ Plan Econ Space 2013;45(2010): 2495-514. https://doi.org/10.1068/a45490.

[39] Liao FH, Farber S, Ewing R. Compact development and preference heterogeneity in residential location choice behaviour: a latent class analysis. Urban Stud 2015;52 (2):314-37. https://doi.org/10.1177/0042098014527138.

[40] Speare A. Residential satisfaction as an intervening variable in residential mobility. Demography 1974;11(2):173-88.

[41] Pickvance CG. Life cycle, housing tenure and residential mobility: a path analytic approach. Urban Stud 1974;11(2):171-88. https://doi.org/10.1080/00420987 420080331.

[42] Bach RL, Smith J. Community satisfaction, expectations of moving, and migration. Demography 1977;14(2):147-67.

[43] Abe R, Kato H. Built environment, travel, and residential satisfaction in a developing city: can residents under rapid urbanization agree with a sustainable urban form? Asian Transp Stud 2017;4(3):481-98. https://doi.org/10.11175/easts ats.4.481.

[44] Clark WAV, Davies Withers S. Changing jobs and changing houses: mobility outcomes of employment transitions. J Reg Sci 1999;24(3):273-4. https://doi org/10.1111/0022-4146.00154.

[45] Lu M. "Are pastures greener?" Residential consequences of migration. Int J Popul Geogr 2002;8(3):201-16. https://doi.org/10.1002/ijpg.244.

[46] Liao P. Emotional attachment, residential satisfaction, and mobility propensity. J Popul Stud 2004;(28):49-79.

[47] Green M. Social networks and residential mobility in later life: the effects of moving on social network supportive capacity amongst older people in the UK. 2014. p. 430.

[48] Clark WAV, Onaka J. Life cycle and housing adjustment as explanations of residential mobility. Urban Stud 1983;20(1):47-57. https://doi.org/10.1080/ 713703176.

[49] Addo IA. Assessing residential satisfaction among low income households in multihabited dwellings in selected low income communities in Accra. Urban Stud 2016; 53(4):631-50. https://doi.org/10.1177/0042098015571055.

[50] Molin EJE, Timmermans HJP. Testing hierarchical information integration theory: the causal structure of household residential satisfaction. Environ Plan 2003;35(1): 43-58. https://doi.org/10.1068/a3416.

[51] Feng J, Lin W. Residential satisfaction level and influencing factors of declining old town residents in Suzhou. Prog Geogr 2017;36(2):159-70. https://doi.org/10 $.18306 / \mathrm{dlkxjz.2017.02.003.}$

[52] Wu CH. The role of perceived discrepancy in satisfaction evaluation. Soc Indic Res 2008;88(3):423-36. https://doi.org/10.1007/s11205-007-9200-9.

[53] Muthén BO. Beyond SEM : general latent variable modelling. Behaviormetrika 2002;29(1):81-117. https://doi.org/10.2333/bhmk.29.81.

[54] Jahanshahi K, Jin Y. The built environment typologies in the UK and their influences on travel behaviour: new evidence through latent categorisation in structural equation modelling. Transp Plan Technol 2016;39(1):59-77. https://doi. org $/ 10.1080 / 03081060.2015 .1108083$.

[55] Temelová J, Dvořáková N. Residential satisfaction of elderly in the city centre : the case of revitalizing neighbourhoods in Prague. Cities 2012;29:310-7. https://doi. org/10.1016/j.cities.2011.11.015.

[56] Mohit MA, Adel Mahfoud AK. Appraisal of residential satisfaction in double-storey terrace housing in Kuala Lumpur, Malaysia. Habitat Int 2015;49:286-93. https://d oi.org/10.1016/j.habitatint.2015.06.001.

[57] Clark WAV. Life course events and residential change: unpacking age effects on the probability of moving. J Popul Res 2013;30(4):319-34. https://doi.org/10.100 7/s12546-013-9116-y.

[58] Clark WAV, Maas R. Spatial mobility and opportunity in Australia: residential selection and neighbourhood connections. Urban Stud 2015;53(6):1-15. https://doi.org/10.1177/0042098015572976.

[59] Dempster AP, Laird NM, Rubin DB. Maximum likelihood from incomplete data via the EM algorithm. J R Stat Soc 1977;39(1):1-38.

[60] Muthén BO. Mplus technical appendices. Los Angeles, CA: Muthén \& Muthén; 2004. https://doi.org/10.1017/cbo9780511606434.007.

[61] Muthén BO. Second-generation structural equation modeling with a combination of categorical and continuous latent variables: new opportunities for latent class-latent growth modeling. In: Decade of behavior; 2000. p. 291-322.

[62] Muthen BO, Shedden K. Finite mixture modeling with mixture outcomes using the EM algorithm. Biometrics 1999;55(6):463-9.

[63] Gupta MR, Chen Y. Theory and use of the EM algorithm. Found Trends Signal Process 2010;4(3):223-96. https://doi.org/10.1561/2000000034.

[64] Nylund KL, Asparouhov T, Muthén BO. Deciding on the number of classes in latent class Analysis and growth mixture modeling: a Monte Carlo simulation study. Struct Equ Model 2007;14(4):535-69.

[65] Henson JM, Reise SP, Kim KH. Detecting mixtures from structural model differences using latent variable mixture modeling: a comparison of relative model 
fit statistics. Struct Equ Model 2007;14(2):202-26. https://doi.org/10.1080/1070 5510709336744.

[66] Tekle FB, Gudicha DW, Vermunt JK. Power analysis for the bootstrap likelihood ratio test in latent class models. Adv Data Anal Classif 2016;10(2):209-24.

[67] Carragher N, Adamson G, Bunting B, McCann S. Subtypes of depression in a nationally representative sample. J Affect Disord 2009;113(1-2):88-99. htt ps://doi.org/10.1016/j.jad.2008.05.015.

[68] Huang X, Dijst M, van Weesep J, Zou N. Residential mobility in China: home ownership among rural-urban migrants after reform of the hukou registration system. J Hous Built Environ 2014;29(4):615-36. https://doi.org/10.1007/s1090 1-013-9370-5.

[69] Huang Z, Du X. Assessment and determinants of residential satisfaction with public housing in Hangzhou, China. Habitat Int 2015;47:218-30. https://doi.org/10.10 16/j.habitatint.2015.01.025.

Wen Jiang is a lecturer at Chongqing University, China. She holds her PhD in Urban Planning Group, Eindhoven University of Technology, the Netherlands. Her research interests include urban redevelopment, residential mobility and residential satisfaction. Her current research mainly focuses on the statistical analysis and modelling of residential behaviour and residential satisfaction regarding renovated urban areas. Her work has been published in several international journals. She has also served as reviewer of journals.

Tao Feng is an Assistant Professor in Eindhoven University of Technology. His main research field is transportation where he looks into various topics relating to travel demand forecasting, travel behaviour analysis, (big) data and travel surveys. He is the associated editor of journal Asia Transport Studies. He serves on committee members for several international conferences and reviewer for many journals/conferences. His research funding are related to smart cities, big data, energy and transportation.

Harry JP Timmermans is Head of the Urban Planning Group of the Eindhoven University of Technology, the Netherlands. He has research interests in modeling decision-making processes and decision support systems in a variety of application domains, including transportation. He is editor of the Journal of Retailing and Consumer Services, and serves on the board of several other journals in transportation, geography, urban planning, marketing, artificial intelligence and other disciplines. He is co-chair of the International Association of Travel Behavior Research (IATBR), and member of several scientific committees of the Transportation Research Board. He has also served as member of conference committees in transportation and artificial intelligence. 